REVIEW

\title{
Corticosteroids in the management of the paediatric epilepsies
}

\author{
R Gupta, R Appleton
}

Arch Dis Child 2005;90:379-384. doi: 10.1136/adc.2004.051375

Corticosteroids (predominantly prednisolone and hydrocortisone) and adrenocorticotropic hormone (ACTH) have been used in the treatment of the epilepsies for over 50 years. ${ }^{2}$ Over the past 30 years most reports have focused on epilepsy syndromes and epileptic encephalopathies resistant to treatment with the more conventional anticonvulsant and antiepileptic drugs (AEDs) and specifically West syndrome. There has been relatively little attention on the role of corticosteroids in treating other epilepsies.

See end of article for authors' affiliations

Correspondence to Dr R Appleton, The Roald Dahl EEG Unit,

Department of Neurology, Royal Liverpool Children's NHS Trust (Alder Hey), Eaton Road, Liverpool L12 2AP, UK; richard.appleton@ rlch-tr.nwest.nhs.uk

Accepted 19 October 2004
$\mathrm{T}$ he purpose of this paper is to review the use of corticosteroids in the management of epilepsy and to briefly outline some of the proposed (but largely unproven), mechanisms of action of these drugs. It is not the aim of this paper to write either a Cochrane review or a meta-analysis, firstly because a Cochrane review of the treatment of infantile spasms (IS) has been published recently, ${ }^{3}$ and secondly because the data of children with epilepsy syndromes other than West syndrome are limited (and typically non-randomised) and therefore tend to preclude these more formal approaches. Finally, in view of the paucity and quality of evidence it would seem inappropriate for this review to provide any definitive recommendations on when and how corticosteroids should be prescribed in treating the paediatric epilepsies.

WEST SYNDROME (INFANTILE SPASMS)

In 1958, Sorel and Dusaucy-Bauloye ${ }^{4}$ showed that ACTH was effective in treating children with infantile spasms (IS), resulting in not only seizure control, but also improvements in behaviour and the electroencephalogram (EEG), findings that were confirmed in further studies over the following year. ${ }^{5-8}$ Subsequently, most published reports have, predictably, addressed and evaluated the use of corticosteroids and/or ACTH in IS in view of its typically explosive and distressing presentation and poor outcome, with persisting seizures and developmental/cognitive impairment. However, most studies have been uncontrolled, retrospective, and have used a wide range of different corticosteroid preparations and dose regimes. ${ }^{9}$ Furthermore, although West syndrome may be homogeneous in terms of its defining criteria (age at onset, occurrence of IS, and hypsarrhythmia), it is extremely heterogeneous in terms of its electroclinical phenotype and aetiologies. The fact that IS may be caused by or be associated with so many different aetiologies (even including no identified cause in at least $10-20 \%$ of patients) would suggest a possible "final common pathophysiological pathway", the end-point being the development of spasms and typically within the first year of life.

Surveys have shown that corticosteroids or ACTH continue to be used as the first line treatment choice for IS $^{10-12}$ although debate persists on many aspects of the treatment of IS. These include the most appropriate preparation-oral corticosteroids (specifically, prednisolone) or intramuscular ACTH (or, in the UK, because this drug is no longer available, its "equivalent", tetracosactide or tetracosactrin), the most appropriate dose, the most appropriate regime, and the most effective duration of treatment. ${ }^{13-17}$ It is generally accepted that oral corticosteroids or ACTH will reduce or stop IS and normalise EEG findings in between $50 \%$ and $75 \%$ of patients within a week or two of starting treatment. $^{917-19}$ Some studies have reported no difference in efficacy between prednisolone and ACTH, ${ }^{20-22}$ while others have shown a better outcome with ACTH. ${ }^{23}{ }^{24}$ In a double blind study by Hrachovy and colleagues, ${ }^{22}$ patients were randomised to receive either 20 international units (iu)/day of ACTH intramuscularly plus prednisolone placebo orally or prednisolone at a dose of $2 \mathrm{mg} / \mathrm{kg} /$ day plus ACTH placebo for two weeks. If seizure control was achieved, treatment was tapered over one week, and if seizure control was not achieved, the patient was crossed over to the other treatment regime. There was no difference in efficacy between the two regimes. In contrast, Baram and colleagues, ${ }^{23}$ in a single blind study of 29 patients with IS randomly treated with either high dose ACTH (150 units/ $\mathrm{m}^{2} /$ day $)$ or prednisone $(2 \mathrm{mg} / \mathrm{kg} /$ day $)$ for two weeks showed that $86 \%$ of the ACTH treated and $28 \%$ of the prednisone treated patients achieved resolution of the spasms and hypsarrhythmia. The preliminary results of a national study of over 200 children with newly diagnosed IS of non-tuberous sclerosis origin (the United Kingdom Infantile Spasm Study, UKISS), showed that after two weeks of treatment, spasm suppression was achieved in 40 of the 55 (73\%) children randomised to treatment with steroids (oral prednisolone or intramuscular tetracosactide) compared to 28 of the $52(54 \%)$ children randomised to treatment with vigabatrin. ${ }^{25}$

Other studies using higher doses of ACTH standardised to body surface area have shown conflicting results. ${ }^{192627}$ Lombroso $^{19}$ found no short term difference in spasm control between ACTH $\left(110 \mathrm{iu} / \mathrm{m}^{2} /\right.$ day $)$ and prednisolone 
( $2 \mathrm{mg} / \mathrm{kg} /$ day). However, Snead ${ }^{26} 27$ achieved control of spasms in $90 \%$ of patients treated with ACTH $\left(150 \mathrm{iu} / \mathrm{m}^{2} /\right.$ day) compared with only $40 \%$ of patients treated with prednisolone ( $2 \mathrm{mg} / \mathrm{kg} / \mathrm{day})$. Oral hydrocortisone ( $15 \mathrm{mg} / \mathrm{kg}$ / day) given for one month, led to seizure freedom in five of 11 infants with IS due to tuberous sclerosis. ${ }^{28}$ Previous surveys of the medical treatment of infantile spasms by paediatric neurologists in the USA, Japan, and the UK, have shown that when corticosteroids are used, ACTH is generally preferred to oral preparations (particularly prednisolone). ${ }^{10-12}$

Rarely, intravenous dexamethasone has been used to treat West syndrome. In a comparative study of 10 patients with symptomatic IS, five treated with seven doses of intravenous dexamethasone given over three months and five treated with intramuscular ACTH given over six weeks, spasms and hypsarrhythmia resolved in all. However, at final follow up (which was under three months), patients in both groups had shown either a relapse in spasms (in two of the five patients treated with ACTH) or the development of partial seizures (in two of the five children treated with dexamethasone and one of the five children treated with ACTH). ${ }^{29}$

Controversy also exists regarding the relation between the duration of spasms prior to diagnosis and response to treatment in terms of both the short and long term (specifically developmental and cognitive) outcome. ${ }^{19} 2230$ Hrachovy and colleagues, ${ }^{22}$ and Glaze and colleagues, ${ }^{31}$ in prospective studies found no relation between the duration of spasms before treatment and outcome. In contrast, Lombroso $^{19}$ in a prospective, and Singer and colleagues, ${ }^{30}$ in a retrospective study, found that patients treated with ACTH within one month of the onset of spasms had a better outcome than those in whom ACTH therapy was delayed for more than one month. However, the findings, conclusions, and implications of Lombroso's study ${ }^{19}$ —and potentially all studies that have evaluated the steroid treatment of IS-must be questioned in view of their methodology.$^{14}$ Concerns about the methodology of one specific study ${ }^{19}$ are many, including: patients were collected over an 18 year period and were evaluated prior to the availability of detailed neuroimaging and more sophisticated metabolic studies, which would clearly influence the proportion of cryptogenic (idiopathic) and symptomatic cases; children within the "cryptogenic" group were almost certainly a heterogeneous group in terms of sex, age of onset, age at treatment of spasms, and developmental status; although the patients appeared to receive just one drug $(\mathrm{ACTH})$, this was in different doses and regimes; the outcome measures were limited to "intelligence quotient (IQ) $>80$ versus $<80^{\prime \prime}$ and "seizures or no seizures"; the critical treatment lag period (time from onset of spasms and diagnosis to treatment) of 30 days appears to have been chosen arbitrarily; and finally, there was an unequal distribution of children who were treated within 30 days of onset of spasms (21 patients) and those treated after 30 days (51 patients). ${ }^{14}$ More recently, a study of 18 children with Down's syndrome and IS, who were followed up for a mean of 85 (range 32-180) months, showed that in those treated "early" and within two months of onset, spasm control was easier, subsequent seizures were less "persistent", developmental quotients were higher, and there was a lower score of autistic features. ${ }^{32}$ Although this was a small study using different drugs and dose regimes, this is a potentially important observation and needs to be confirmed by undertaking further long term studies (with a minimum of five years follow up) in specific aetiologies of IS. Although the time to diagnosis and initiation of treatment may well contribute to the long term developmental/cognitive outcome of children with IS, the predominant factor is likely to be the underlying cause of the spasms.

\section{OTHER EPILEPSIES AND EPILEPSY SYNDROMES}

Studies on the use of corticosteroids and ACTH in the treatment of epilepsy outside infancy are limited..$^{28} 34$ It is often suggested and practised that corticosteroids and ACTH as well as other "alternative" treatments for epilepsy, including the ketogenic diet and immunoglobulins, may have a role in treating the more severe childhood epilepsies, including the epileptic encephalopathies, that are resistant to more conventional antiepileptic treatments. ${ }^{35} 36$ However, little is known about the efficacy, mechanism of action, or the safety of such treatments. ${ }^{36}$

Snead and colleagues ${ }^{26}$ described their experience of treating 116 children with epilepsy with either prednisone or ACTH. Fifty two children had IS and the remaining 64 children had myoclonic seizures without EEG evidence of hypsarrhythmia or other intractable seizures. Prednisone was given at a dose of $3 \mathrm{mg} / \mathrm{kg} /$ day for four weeks, followed by $3 \mathrm{mg} / \mathrm{kg}$ on alternate days for four weeks and then at a tapering dose for the final four weeks. ACTH was given at a dose of $150 \mathrm{iu} / \mathrm{m}^{2} /$ day for one week, followed by $75 \mathrm{iu} / \mathrm{m}^{2} /$ day for one week, $75 \mathrm{iu} / \mathrm{m}^{2} /$ day on alternate days for two weeks, and then withdrawn gradually over the subsequent eight weeks. Of the 64 children with seizure types other than IS, 34 received ACTH and the remaining 30, prednisone. Seizures were effectively controlled in $25(73 \%)$ of the ACTH treated children, but in none of the prednisone treated children. ${ }^{26}$

Corticosteroids, including ACTH, may also be effective in treating children with Lennox Gastaut syndrome (LGS)..$^{36-38}$ In the study by Yamatogi and colleagues, ${ }^{37}$ all 45 children with LGS received ACTH in doses ranging from $10 \mathrm{iu} /$ day for infants to $30 \mathrm{iu} /$ day for older children. The duration of treatment varied considerably, ranging from 10 to 57 days. Twenty three $(51 \%)$ of the children became seizure free for over 10 days, but $18(78 \%)$ of these children later relapsed. The patients' clinical improvement was generally reflected in an improvement in their EEGs. O'Regan and Brown ${ }^{38}$ reported that six of seven children with LGS and intractable seizures treated with ACTH (20 iu/day for two weeks followed by a gradual withdrawal over the succeeding weeks) showed improved seizure control and EEG findings. The majority also showed improved behaviour and communication. It is unclear which seizure type or types showed the best response, including possible episodes of electrical or nonconvulsive status epilepticus. Sinclair ${ }^{39}$ treated 10 children with LGS and intractable seizures with prednisolone (1 mg/ $\mathrm{kg}$ /day for six weeks followed by withdrawal over the next six weeks) and achieved seizure freedom in seven and seizure reduction in three children, although it is unclear as to how long this improvement was maintained.

Successful treatment of Landau-Kleffner syndrome (LKS) with corticosteroids and ACTH has also been reported, ${ }^{38} 4041$ and both are currently considered as drugs of first choice, used either alone or in conjunction with sodium valproate. In the study by Marescaux and colleagues, ${ }^{40}$ two children received pulsed doses of hydrocortisone ( $12 \mathrm{mg} / \mathrm{kg} / \mathrm{day})$ and a third received only prednisolone $(2 \mathrm{mg} / \mathrm{kg} /$ day for one month followed by $1 \mathrm{mg} / \mathrm{kg} /$ day for one month and then $1 \mathrm{mg} / \mathrm{kg} /$ day on alternate days). All three children showed improved speech, suppression of seizures, and normalisation of the EEG. Lerman and colleagues ${ }^{41}$ reported their experience in treating four children with LKS; a 5 year old received ACTH ( $80 \mathrm{iu}$ /day tapered over three months), a 6 and a 7 year old received prednisolone $(60 \mathrm{mg} /$ day for up to two months, tapered over the next three months), and a 9 year old received dexamethasone ( $4 \mathrm{mg} /$ day for two weeks, tapered over the following three months). All four children showed normalisation of the EEG, long lasting remission of the aphasia, and improvement of seizure control. O'Regan and Brown, in their series of 23 children, successfully treated the 
six children with epileptic aphasia using ACTH in the regime described previously. ${ }^{38}$ Unfortunately, the significance of all of these results is limited by the lack of long term outcome data on the speech and language pattern and psychosocial functioning of these patients in adult life. Epilepsy with continuous spike wave discharges (CSWSS) or "epilepsy with electrical status epilepticus of slow sleep" (ESESS) ${ }^{42} 43$ shows certain similarities with LKS, and it has been suggested that the two disorders are part of the spectrum of seizure related aphasia. ${ }^{42}$ Consequently, it has been suggested that CSWSS/ ESESS may also respond to treatment with corticosteroids or ACTH, although there is limited evidence for this hypothesis. ${ }^{43} 44$

Myoclonic or myoclonic-astatic ("drop") seizures, often because of their frequency, acute and frequently encephalopathic presentation, medical intractability, and tendency to result in physical injury, have also been treated with corticosteroids. Sinclair, using a regime described earlier, treated nine children with myoclonic epilepsy. ${ }^{39}$ Five became seizure free (at least initially), two showed a reduction, and the remaining two showed no change in their seizures. $\mathrm{O}^{\prime}$ Regan and Brown ${ }^{38}$ observed no improvement in their one child with severe myoclonic epilepsy in infancy (now also known as "Dravet syndrome") treated with ACTH. Similarly, Oguni et al reported only a transient improvement in the myoclonic and absence seizures in five of their 84 patients treated with ACTH. ${ }^{45}$

There are also case reports and small case series describing the use of corticosteroids and ACTH in other epilepsy syndromes. ${ }^{38}{ }^{46-49}$ Sinclair treated seven children with absence epilepsy, all "improving" and five becoming seizure-free. ${ }^{39}$ Hart and colleagues ${ }^{46}$ described a temporary improvement in seizure control in 10 of 17 patients with Rasmussen's syndrome (chronic encephalitis and epilepsy) receiving corticosteroids, and Carillo Herranz and colleagues ${ }^{47}$ described a 5 year old boy with Rasmussen's syndrome successfully treated with immunoglobulins and corticosteroids. High dose corticosteroid treatment of epilepsia partialis continua has also been described ${ }^{48}{ }^{49}$ and there is a single case report of the successful treatment using steroids in a 17 year old girl with status epilepticus of frontal lobe origin. ${ }^{50}$

Finally, corticosteroids and specifically, dexamethasone and methylprednisolone, are frequently used in the management of patients with acute symptomatic seizures complicating bacterial or viral meningitis/meningoencephalitis, demyelination (acute disseminated encephalomyelitis and multiple sclerosis), cerebral vasculitis, and brain tumours. In these situations the use of corticosteroids is largely empiric and targeted more at the underlying disease process (specifically to shorten time to recovery and reduce the risk of secondary sequelae), rather than the seizures themselves.

\section{MECHANISM OF ACTION OF CORTICOSTEROIDS}

There is no animal model that shows the seizure type of infantile spasms. In view of this, the mechanism of action of corticosteroids and ACTH on seizures in general, and spasms in particular, remains unclear and largely speculative. Various explanatory and largely speculative hypotheses have been formulated, ${ }^{9} 303940$ 51-53 many of which are discussed in detail by $\mathrm{O}^{\prime}$ Regan and Brown. ${ }^{38}$ These include the correction of deficient or dysfunctional enzymes or enzyme systems, changes in intracellular-extracellular electrolyte ratios, correction of hypoglycaemia or low intracellular glucose, reduction in cerebral water content, an anti-inflammatory action, and immune modulation or suppression. ACTH may also have other mechanisms of action, including acting through the hypothalamic-pituitary-adrenal axis to stimulate the adrenal gland to produce glucocorticoids and, through negative feedback, suppressing corticotrophin releasing hormone (CRH). It may also act as a modulator of intracellular neurosteroid and adenosine production with an additional, indirect effect ("second messenger" effect) on the $\mathrm{GABA}_{\mathrm{A}}$ receptor. ${ }^{35}$ It has been postulated that $\mathrm{CRH}$, the production and release of which is increased at times of "stress" may result in neuronal hyperexcitability (specifically within the limbic system and brain stem), which consequently, in an immature brain, may facilitate the development of IS. ${ }^{54} \mathrm{ACTH}$, by suppressing the synthesis of CRH may then "switch off" the spasms, possibly at receptor level and possibly involving specific ion channels. Although this mechanism might explain some of the pathophysiology of IS in some situations, it may be more difficult to apply this hypothesis in those infants with idiopathic or cryptogenic spasms, who have no evidence of any "stress". The clear observation that corticosteroids tend to work rapidly (often within days of administration) would tend to support an anti-inflammatory or direct neurotransmitter, rather than an immune modulated or hormonal hypothesis. Finally, if one accepts that ACTH is more effective than prednisolone, this would support an extra-adrenal mechanism of action of exogenous ACTH and therefore the possibility of a direct, including specific anticonvulsant effect on neural tissue, including either the cerebral cortex or brain stem. A direct neurotransmitter and anticonvulsant-like effect would potentially contradict a pituitary-adrenal mechanism of action as exogenous ACTH (or tetracosactrin) would be likely to suppress endogenous ACTH production, which might then be expected to exacerbate rather than improve spasm control. There is some electrophysiological evidence for a potential anticonvulsant/neurotransmitter effect and specifically for fragments of the peptide that have no inherent corticotrophic activity. ${ }^{556}$ To date, evidence for these fragments exerting any anticonvulsant effect is very limited and has been derived from animal studies that have given conflicting results. ${ }^{57-59}$ More recently, levels of beta-nerve growth factors (NGF) and nitric oxide (NO) have been found to be reduced in the cerebrospinal fluid of infants with symptomatic, but not cryptogenic, IS.$^{60}$ It is unclear whether this is a primary or secondary effect and whether NGF or NO (or neither) has any role in the pathogenesis of IS.

Attention has also focused on a group of neuroactive steroids that may modulate neuroaxonal excitability and have inherent anticonvulsant or antiepileptic activity. These steroids are related to sex hormones, which in contrast to testosterone and corticosteroids, are recognised to have weak proconvulsant (oestrogen) and more importantly, anticonvulsant (progesterone and its metabolites) effects. ${ }^{61-64}$ One of these drugs, ganaxolone-an "epalon", a shortened form of epiallopregnanolone ${ }^{64}$-has been shown to be effective in treating partial seizures and IS, and without the potentially severe side effects associated with ACTH and prednisolone. Further data are clearly required to assess not only the effectiveness but also, and arguably more importantly, the relative efficacy of this potentially less "toxic" and more specific neuroactive steroid, compared to prednisolone, ACTH, or hydrocortisone.

\section{SIDE EFFECTS OF CORTICOSTEROIDS}

Treatment with both prednisolone and ACTH may cause significant side effects, including irritability, the development of Cushing syndrome, electrolyte disturbances (specifically hypokalaemia), hyperglycaemia, and glucose intolerance, osteoporosis, infections, hypertension, and a usually reversible dilatation of the ventricular and extra-ventricular cerebrospinal fluid spaces. ${ }^{18}{ }^{65-69}$ However, the more serious side effects have been reported predominantly with ACTH rather than prednisolone and have included severe sepsis resulting in death ${ }^{18}{ }^{68}$ and cardiac hypertrophy. ${ }^{66}{ }^{67}$ Although 
these side effects are more likely to be associated, and become more marked, with prolonged use (over many weeks), they may still develop within days of administration. Synthetic rather than natural ACTH is also considered to be more frequently associated with more serious side effects. ${ }^{70}{ }^{71}$ However, synthetic ACTH (tetracosactrin), which has the same amino acid sequence as the first 24 residues of the 39 amino acids of natural ACTH, is considered to be less antigenic than ACTH and is therefore less likely to cause allergic reactions than the natural molecule. Finally, the long term use of steroids (over many months) to maintain any initial benefit or to try and modify any underlying and potentially evolving progressive disorder may be complicated by immunosuppression, glucose intolerance, and osteoporosis. Inevitably, in view of these potential adverse side effects and practical difficulties, the use of corticosteroids in the treatment of the epilepsies (whether used in preference to, or in conjunction with, the more conventional antiepileptic drugs), must be determined on a risk:benefit basis and with some knowledge of their mechanism of action as well as with informed discussion with the family.

\section{SUMMARY}

Corticosteroids are clearly established as first line treatments of IS (West syndrome) and the Landau-Kleffner syndrome (LKS). This is typically as monotherapy in West syndrome, but often in conjunction with more conventional AEDs (commonly, sodium valproate, or the benzodiazepines (clobazam)) in LKS. Their use and role in other seizure types, including in epileptic spasms occurring outside infancy, Lennox-Gastaut syndrome, severe myoclonic epilepsy in infancy, and other epilepsy syndromes is far less clear and defined; in these situations steroids are typically used in conjunction with drugs such as sodium valproate, topiramate, and lamotrigine (depending on the specific syndrome), and often during acute exacerbations, including episodes of non-convulsive status epilepticus that frequently complicate these syndromes. There is little evidence to support the hypothesis that steroids may be of use in the early and explosive onset epileptic encephalopathies, including Rasmussen's encephalitis where there may be an autoimmune or post-infectious, inflammatory cause. However, in these usually catastrophic disorders, it would seem reasonable and acceptable to use steroids (either alone or in combination with immunoglobulins), and probably as early as possible after the child's initial presentation-in view of their natural history, particularly Rasmussen's encephalitis.

There is no consensus of opinion on the steroid doses and treatment regimes that are most effective; in part this reflects the type of ACTH preparation used (natural versus synthetic) and the fact that different investigators determine the dose based on body weight and others on body surface area. There is also considerable variation in the dose of prednisolone, ranging from $<2$ to $>2 \mathrm{mg} / \mathrm{kg} /$ day. Generally, there does appear to be a dichotomy of views, with some advocating as low a dose of ACTH or prednisolone as possible, ${ }^{72}$ and others recommending a more aggressive approach, irrespective of the aetiology of the spasms and whether cryptogenic or symptomatic in origin..$^{51}$ This variation in practice is further complicated by using different preparations, including oral (prednisolone, hydrocortisone, betamethasone, dexamethasone, and possibly in the future, ganaxolone), intramuscular (ACTH or tetracosactide/tetracosactrin in the UK), and intravenous (methylprednisolone, dexamethasone) preparations. It remains unclear whether intravenous methylprednisolone, intramuscular ACTH, or oral prednisolone should be used in the early and aggressive treatment of the epileptic encephalopathies in view of the unknown mechanism(s) of action of corticosteroids. The preparation of the ACTH may also be important as it has been suggested that the impurities in some preparations may reduce its effectiveness and increase the incidence of side effects. ${ }^{15}$ The risk and incidence of side effects (mild and severe) that may be associated with corticosteroid treatment must also be considered and balanced against the potential benefits, particularly in the long term. The evidence base for such treatments remains poor, and further studies-specifically, randomised control trials-are needed. The short term results of one of these studies - the UKIS Study ${ }^{25}$ - have, perhaps predictably, confirmed the findings of previous randomised and open studies favouring corticosteroids (ACTH or prednisolone) rather than vigabatrin in treating IS of non-tuberous sclerosis origin. Vigabatrin has previously been shown to be particularly effective and possibly superior to corticosteroids for both spasm suppression and short term developmental outcome, in the treatment of IS due to tuberous sclerosis. ${ }^{28}$ It is unlikely that the UKIS Study will provide any definitive information on the long term outcome of patients with IS (specifically, cognitive function and the development of different seizure types and epilepsies) because of its provisional limited period of follow up. Unfortunately this is equally true of most other prospective and randomised studies, which have employed only relatively short periods of follow up. The long term outcome is of equal, if not greater, importance than any immediate or short term effect on the spasms or seizures in any of the epileptic encephalopathies, including West syndrome.

A recent review of the literature on the medical treatment of IS, conducted by the American Academy of Neurology (AAN) and the American Child Neurology Society (CNS) concluded that ACTH is probably effective, and that vigabatrin is possibly effective for the short term treatment of IS. $^{73}$ However, the working group of the AAN and CNS found that the data were insufficient to make any recommendations regarding the use of ACTH, corticosteroids, vigabatrin, and other agents to improve the long term outcomes (in terms of later seizure control and development) of children with IS; the authors also found no evidence that early and successful treatment improves the long term outcome of children with IS. ${ }^{73}$ The preliminary observation by Eisermann et al is clearly important as it would suggest that early treatment may be associated with an improved outcome, both in terms of cognitive function and later epilepsy, at least in one specific disorder. ${ }^{32}$

Finally, it would be potentially very important to obtain randomised controlled trial evidence to determine whether early treatment with corticosteroids may improve the long term outcome (epilepsy, cognitive function) of some of the other epileptic encephalopathies-specifically Ohtahara's syndrome, migrating partial epilepsy in infancy, severe myoclonic epilepsy of infancy, and Rasmussen's encephalitis. The concept of "switching off" an evolving and potentially epileptogenic and degenerative process that may otherwise result in chronic epilepsy and developmental stagnation or regression is attractive; whether corticosteroids could fulfil this role is currently unclear. Assessing this concept or hypothesis would clearly necessitate multicentre, national, or international collaboration because of the rarity and aetiological heterogeneity of most of these conditions-but this practical difficulty should not preclude such studies.

Until and unless more evidence becomes available, pride, prejudice, and personal experience are likely to continue to determine when and how corticosteroids are used in treating the paediatric epilepsies, including IS. In the authors' practice, vigabatrin remains an effective and initial first line treatment for IS using a protocol outlined previously. ${ }^{74}$ It is recommended that the advice of a paediatric neurologist always be sought for the management of children with the 
other, more malignant epilepsies including Ohtahara's syndrome, Lennox-Gastaut syndrome, severe myoclonic epilepsy of infancy, episodes of non-convulsive status epilepticus and Rasmussen's encephalitis, and specifically when considering the use of corticosteroids in these epilepsy syndromes.

\section{Authors' affiliations}

\section{R Gupta, R Appleton, The Roald Dahl EEG Unit, Department of} Neurology, Royal Liverpool Children's NHS Trust (Alder Hey), Liverpool, UK

Competing interests: none declared

\section{REFERENCES}

1 McQuarrie I, Anderson JA, Ziegler MR. Observation on the antagonistic effects of posterior pituitary and cortico-adrenal hormones in the epileptic subject. J Clin Endocrinol 1942;2:406-10.

2 Klein R, Livingston S. The effect of adrenocorticotrophic hormones in epilepsy J Paediatr 1950;37:733-42.

3 Hancock E, Osborne JP, Milner P. Treatment of infantile spasms (Cochrane Review). In: The Cochrane Library, Issue 4. Oxford: Update Software, 2002.

4 Sorel L, Dusaucy-Bauloye A. A propos de 21 cas d'hypsarhythmia de Gibbs. Son traitement spectaculaire par l'ACTH. Acta Neurol Psychiatr Belg 1958;58:130-41.

5 Low NL. Infantile spasms with mental retardation: II. Treatment with cortisone and adrenocorticotropin. Pediatrics 1958;22:1165-9.

6 Dumermuth G. Uber die Blitz-Nick-Salaam-Krampfe und ihre Behandlung mit ACTH und hydrocortison. Vorlaufige Mitteilung. Helv Paediatr Acta 1959; 14:250-70.

7 Gastaut H, Saltiel J, Raybaud C, et al. A propos du traitement par l'ACTH des encephalites myoclonique de la premiere enfance avec majeure (hypsarhythmia). Pediatrie 1959;14:35-45.

8 Stamps FW, Gibbs EL, Rosenthal IM, et al. Treatment of hypsarrhythmia with ACTH. JAMA 1959;171:408-11.

9 Snead OC, III. Other antiepileptic drugs: adrenocorticotrophic hormone (ACTH). In: Levy R, Mattson R, Meldrum B, et al, eds. Antiepileptic drugs. New York: Raven Press, 1989:905-12.

10 Bobele GB, Bodensteiner JB. The treatment of infantile spasms by child neurologists. J Child Neurol 1994;9:432-5.

11 Watanabe K. Medical treatment of West syndrome in Japan. J Child Neurol 1995;10:143-7.

12 Appleton RE. The treatment of infantile spasms by paediatric neurologists in the UK and Ireland. Dev Med Child Neurol 1996;38:278-9.

13 Hrachovy RA, Frost JD, Glaze DC. High dose, long duration versus low-dose, short duration corticotropin therapy for infantile spasms. J Pediatr 1994; 124:803-6.

14 Appleton RE. West syndrome: long-term prognosis and social aspects. Brain Dev $2001 ; 23: 688-91$

15 Baram TZ. What are the reasons for the strikingly different approaches to the use of ACTH in infants with West syndrome? Brain Dev 2001;23:647-8.

16 Matsumoto A, Watanabe K, Negoro T, et al. Infantile spasms: etiological factors, clinical aspects, and long term prognosis in 200 cases. Eur J Pediatr 1981;135:239-4.

17 Riikonen R. A long-term follow-up study of 214 children with the syndrome of infantile spasms. Neuropediatrics 1982;13:14-23.

18 Riikonen R, Donner M. ACTH therapy in infantile spasms: side effects. Arch Dis Child 1980;55:664-72.

19 Lombroso CT. A prospective study of infantile spasms. Clinical and therapeutic correlations. Epilepsia 1983;24:135-58.

20 Jeavons PM, Bower BD. Infantile spasms: a review of the literature and a study of 112 cases. London: Heinemann, 1964.

21 Jeavons PM, Bower BD, Dimitrakoudi M. Long term prognosis of 150 cases of "West syndrome". Epilepsia 1973;14:153-64.

22 Hrachovy RA, Frost JD, Kellaway PR, et al. Double-blind study of ACTH vs. prednisone therapy in infantile spasms. J Pediatr 1983;103:641-5.

23 Baram TZ, Mitchell WG, Tourney A, et al. High-dose corticotropin (ACTH) versus prednisone for infantile spasms: a prospective, randomized blinded study. Pediatrics 1996;97:375-9.

24 Sher PK, Sheikh MR. Therapeutic efficacy of ACTH in symptomatic infantile spasms with hypsarrhythmia. Pediatr Neurol 1993;9:451-6.

25 Lux AL, Edwards SW, Hancock E, et al. The United Kingdom Infantile Spasms Study comparing vigabatrin with prednisolone or tetracosactide at 14 days: a multicentre, randomised controlled trial. Lancet 2004;364:1773-8.

26 Snead OC III, Benton JW, Myers GJ. ACTH and prednisone in childhood seizure disorders. Neurology 1983;33:966-70.

27 Snead OC III, Benton JW Jr, Hosey LC, et al. Treatment of infantile spasms with high-dose ACTH: efficacy and plasma levels of ACTH and cortisol. Neurology 1989;39:1027-31.

28 Chiron C, Dumas C, Jambaque I, et al. Randomised trial comparing vigabatrin and hydrocortisone in infantile spasms due to tuberous sclerosis. Epilepsy Res 1997;26:389-95.

29 Yamamoto $\mathbf{H}$, Asoh M, Murakami H, et al. Liposteroid (dexamethasone palmitate) therapy for West syndrome: a comparative study with ACTH therapy. Pediatr Neurol 1998;18:415-19.
30 Singer WD, Rabe EF, Haller JS. The effect of ACTH therapy on infantile spasms. J Pediatr 1980;96:485-9.

31 Glaze DG, Hrachovy RA, Frost JD, et al. Prospective study of outcome of infants with infantile spasms treated during controlled studies of ACTH and prednisone. J Pediatr 1988;1 12:389-96.

32 Eisermann MM, DeLaRaillere A, Dellatolas G, et al. Infantile spasms in Down syndrome-effects of delayed anticonvulsive treatment. Epilepsy Res 2003;55:21-7

33 Riikonen R. Current knowledge of action of ACTH and corticosteroids. Brain Dev 1987;9:409-14.

34 Schmidt D. Diagnostic and therapeutic management of intractable epilepsy. In: Schmidt D, Morselli PL, eds. Intractable epilepsy: experimental and clinical aspects. New York: Raven Press, 1986:237-57.

35 Aicardi J. Clinical approach to the management of intractable epilepsy. Dev Med Child Neurol 1988;30:429-40.

36 Prasad AN, Stafstrom CF, Holmes GL. Alternative epilepsy therapies: the ketogenic diet, immunoglobulins, and steroids. Epilepsia 1996;37(suppl 1):S81-95.

37 Yamatogi Y, Ohtsuka Y, Ishida T, et al. Treatment of the Lennox syndrome with ACTH: a clinical and electroencephalographic study. Brain Dev 1979;1:267-76.

38 O'Regan ME, Brown JK. ACTH in the treatment of epilepsy. Dev Med Child Neurol 1998;40:82-9

39 Sinclair DB. Prednisone therapy in pediatric epilepsy. Pediatr Neurol 2003;28:194-8.

40 Marescaux C, Hirsch E, Finck S, et al. Landau-Kleffner syndrome: a pharmacologic study of five cases. Epilepsia 1990;31:768-77.

41 Lerman $\mathbf{P}$, Lerman-Sagie T, Kivity S. Effect of early corticosteroid therapy for Landau-Kleffner syndrome. Dev Med Child Neurol 1991;33:257-66.

42 Jayakar PB, Seshia SS. Electrical status epilepticus during slow-wave sleep: a review. J Clin Neurophysiol 1991;8:299-311.

43 Tassinari CA, Rubboli G, Volpi L, et al. Electrical status epilepticus during slow sleep (ESES or CSWS) including acquired epileptic aphasia (Landau-Kleffner syndrome). In: Roger J, Bureau M, Dravet Ch, et al, eds. Epileptic syndromes in infancy, childhood and adolescence, 3rd edn. London: John Libbey, 2002:265-83.

44 Kellermann K. Recurrent aphasia with subclinical bioelectric status epilepticus during sleep. Eur J Pediatr 1978;128:207-12.

45 Oguni H, Hayashi K, Awaya Y, et al. Severe myoclonic epilepsy in infants: a review based on the Tokyo Women's Medical University series of 84 cases. Brain Dev $2001 ; 23: 736-48$

46 Hart YM, Cortez M, Andermann F, et al. Medical treatment of Rasmussen's syndrome (chronic encephalitis and epilepsy): effect of high-dose steroids or immunoglobulins in 19 patients. Neurology 1994;44:1030-6.

47 Carrillo Herranz A, Sanchez Perez I, Aparicio Meix JM, et al. Rasmussen's syndrome, an autoimmune disease. An Pediatr (Barc) 2003;59:187-9.

48 Shahar E, Kramer U, Nass D, et al. Epilepsia partialis continua associated with widespread gliomatosis cerebri. Pediatr Neurol 2002;27:392-6.

49 Olson JA, Olson DM, Sandborg C, et al. Type 1 diabetes mellitus and epilepsia partialis continua in a 6-year-old boy with elevated anti-GAD65 antibodies. Pediatrics 2002;109:e50

50 Akanuma H, Sekijima Y, Tokuda T, et al. A case of severe status epilepticus of frontal lobe origin successfully treated with corticosteroids. Rinsho Shinkeigaku 1998;38:461-4.

51 Snead OC, Chiron C. Medical treatment. In: Dulac O, Chigani HT, Dalla Bernadina B, eds. Infantile spasms and West syndrome. London: WB Saunders, 1994:244-56.

52 Brunson KL, Avishai-Eliner S, Baram TZ. ACTH treatment of infantile spasms: mechanisms of its effects in modulation of neuronal excitability. Int Rev Neurobiol 2002;49:185-97.

53 Riikonen R. Infantile spasms: some new theoretical aspects. Epilepsia 1983;24:159-68

54 Baram TZ. Pathophysiology of massive infantile spasms: perspective on the putative role of the brain adrenal axis. Ann Neurol 1993;33:231-6.

55 Urban I, Lopes de Silva FH, Storm van Leeuwen W, et al. A frequency shift in the hippocampal teta activity: an electrical correlate of central action of ACTH analogues in the dog? Brain Res 1974;69:361-5.

56 Urban I, DeWeid D. Changes in excitability of the theta generating substrate by ACTH 4-10 in the rat. Exp Brain Res 1976;24:325-34.

57 Pentella K, Bachman DS, Sandman CA. Trial of an ACTH 4-9 analog (ORG $2766)$ in children with intractable seizures. Neuropediatrics 1982;13:59-62.

58 Willig RP, Lagenstein I. Use of ACTH fragments in children with intractable seizures. Neuropediatrics 1982;13:55-8.

59 Croiset G, DeWeid D. ACTH: a structure-activity study on pilocarpine-induced epilepsy. Eur J Pharmacol 1992;229:211-16.

60 Riikonen R. ACTH therapy of West syndrome: Finnish views. Brain Dev 2001;23:642-6.

61 Gasior M, Carter RB, Goldberg SR, et al. Anticonvulsant and behavioural effects of neuroactive steroids alone and in conjunction with diazepam. J Pharmacol Exp Ther 1997;282:543-53.

62 Beyenburg S, Stoffel-Wagner B, Bauer J, et al. Neuroactive steroids and seizure susceptibility. Epilepsy Res 2001;44:141-53.

63 Reddy DS, Rogawski MA. Enhanced anticonvulsant activity of neuroactive steroids in a rat model of catamenial epilepsy. Epilepsia 2001;42:337-44.

64 Wiener P. Neuroactive steroids, relaxation and seizure control. Int J Neurosci 2003;113:631-9.

65 Snead OC III. Treatment of infantile spasms. Pediatr Neurol 1990;6:147-50.

66 Lang D, Mühler E, Kupferschmid C, et al. Cardiac hypertrophy secondary to ACTH treatment in children. Eur J Pediatr 1984;142:121-5. 
67 Young RSK, Fripp RR, Stern D Darowish C. Cardiac hypertrophy associated with ACTH therapy for childhood seizure disorder. J Child Neurol 1987;2:311-12.

68 Shamir R, Garty BZ, Rachmel A, et al. Risk of infection during adrenocorticotropic hormone treatment in infants with infantile spasms. Pediatr Infect Dis J 1993;12:913-16.

69 Glaze DG, Hrachovy RA, Frost JD, et al. Computed tomography in infantile spasms: effects of hormonal treatment. Pediatr Neurol 1986;2:23-7.

70 Sorel L. 196 cases of infantile myoclonic encephalopathy with hypsarrhythmia (IMEH: West syndrome) treated with ACTH: danger of synthetic ACTH. Electroencephalographr Clin Neurophysiol 1972;32:571-7.

71 Riikonen RS. Steroid or vigabatrin in the treatment of infantile spasms? Pediatr Neurol 2000;23:403-8.

72 Ito $M$. Extremely low-dose ACTH therapy for West syndrome in Japan. Brain Dev $2001 ; 23: 635-41$

73 Mackay MT, Weiss SK, Adams-Webber T, et al. Practice parameter: medical treatment of infantile spasms. Neurology 2004;62:1668-81.

74 Vigabatrin Paediatric Advisory Group. Guideline for prescribing vigabatrin in children has been revised. BMJ 2000;320:1404-5.

\section{IMAGES IN PAEDIATRICS}

Bronchial artery to bronchial vein fistula secondary to lung nodule resection

$\Lambda$ 7 year old girl presented with a one month history of lethargy, intermittent lower abdominal pain, and an abdominal mass. She was diagnosed as having spindle cell sarcoma of the right kidney following radiological investigations and biopsy of the lesion. She also had an isolated left lung lesion, presumed metastasis, at the time of diagnosis. She was commenced on multi-agent sarcoma chemotherapy. Six months later she underwent right nephrectomy. Three months post-nephrectomy she received radiotherapy to the right flank and both lungs. One year later CT scan of the chest showed a small isolated left upper lobe lesion that was removed by wedge excision. Pathology showed blastemal elements in keeping with a metastatic nodule of a Wilms' tumour, originally a sarcomatous variant; she was treated with topotecan and cyclophosphamide.

CT scan of the chest, performed one month post-lung nodule resection, showed aneurysmal dilatation with two adjacent distended vessels, assumed to be an intercostal artery and vein, both in the left upper lobe. Adjacent pleural thickening was consistent with previous surgery. This aneurysmal dilatation was not seen on previous scans. The CT scan (fig l) showed a serpiginous enhancing vascular structure at the site of the previous nodule and wedge excision. Two vessels were visible on coronal reconstruction coursing to the chest wall, indicating an acquired bronchial artery to bronchial vein fistula that, to our knowledge, has not been previously reported. Systemic artery to pulmonary vein fistulas, ${ }^{1-3}$ and other fistulas such as broncho-pleural, ${ }^{4}$ broncho-oesophageal, ${ }^{5}$ and broncho-biliary, ${ }^{6}$ have been described in the past, but bronchial artery to bronchial vein fistula does not appear to have been reported. We assume surgery to the lung nodule here somehow allowed development of this fistula, and that the prior lung nodule may have had preferential arterial supply from the bronchial rather than the pulmonary arterial circulation. Bronchial artery to bronchial vein fistula may thus be a rare complication of thoracic surgery to the lung. This finding may have been made easier in this case by our recent acquisition of a new, state-of-the-art, 16 slice multi-detector CT scanner which allows faster scanning, and better contrast enhancement with improved spatial resolution. The patient was considered to be in complete remission and has undergone high dose consolidation treatment with melphalan and autologous peripheral blood stem cell rescue.

K McHugh, V Hegde, P Brock, M J Elliott Department of Paediatric Oncology, Radiology, and Cardiothoracic Surgery, Great Ormond Street Hospital, London, UK

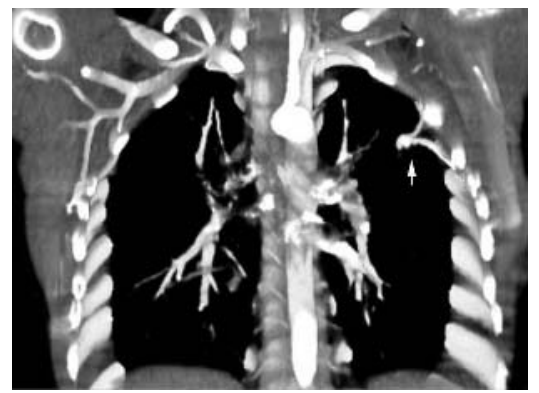

Correspondence to: Dr P Brock, Consultant Paediatric and Adolescent Oncologist, Great Ormond Street Hospital, Great Ormond Street, London WCIN 3JH, UK; brockp@gosh.nhs.uk

\section{References}

1 Pernot C, Simon P, Hoeffel JC, et al. Systemic artery-pulmonary vein fistula without sequestration. Pediatr Radiol 1991;21:158-9.

2 Riehl G, Chaffanjon MD, Frey G, et al. Postoperative systemic artery to pulmonary vessel fistula: analysis of three cases. Ann Thor Surg 2003;76:1873-7.

3 Brundage BH, Gomez AG, Cheitlin MD, et al. Systemic artery to pulmonary vessel fistulas: report of 2 cases and review of the literature. Chest 1972;62: 19-23.

4 Lin J, lannettoni MD. Closure of bronchopleural fistulas using albumin-glutaraldehyde tissue adhesive. Ann Thorac Surg 2004;77:326-8.

5 Kapoor S, Ratan SK, Gathwala G, et al. Bronchoesophageal fistula in a neonate: radionuclide study as diagnostic modality. Am J Perinatol 2003;20:341-5.

6 Jung SI, Goo JM, Han JK, et al. Recurrent bronchobiliary fistula: unsuccessful management with repeated insertion of metallic biliary stent. J Vasc Interv Radiol 2003:14:1577-9. 